\title{
IN HONOUR OF THE SEVENTY-YEAR-OLD GÁBOR FEKETE
}

\author{
A. BORHIDI
}

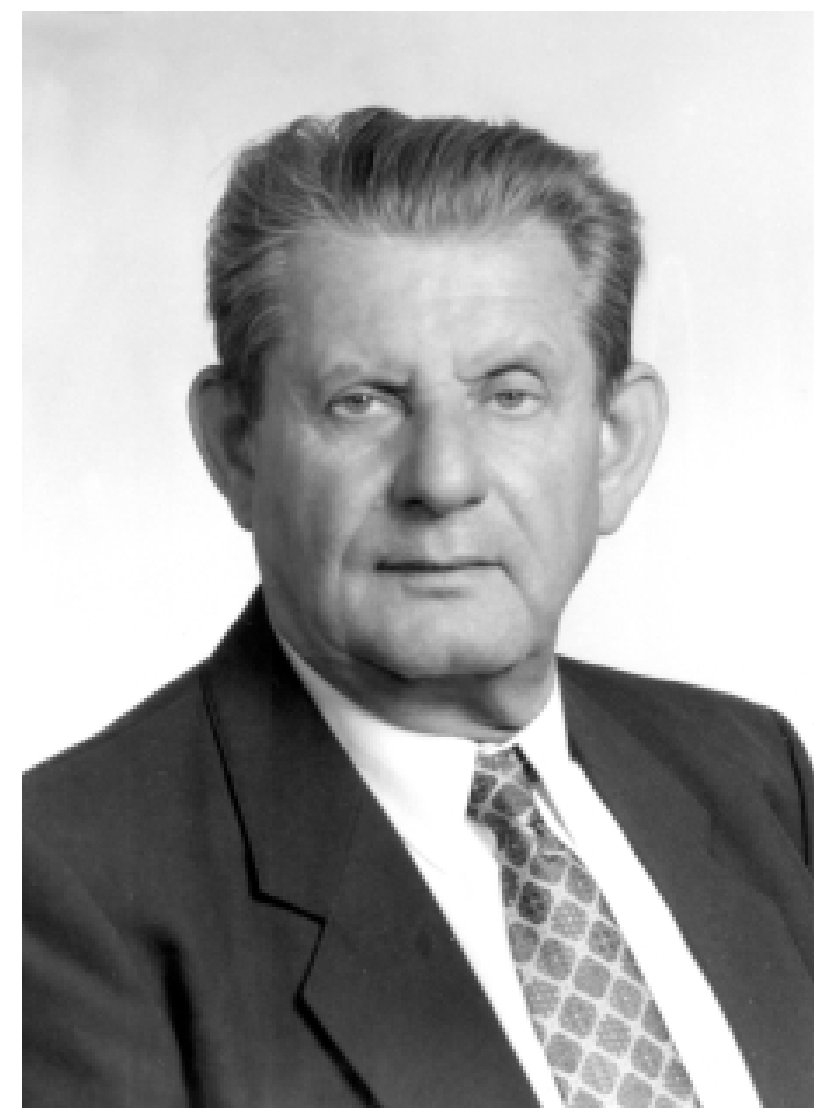

Gábor Fekete was born on 20 April 1930, in Budapest. He spent his childhood in Székesfehérvár, and also attended his schools there. He graduated from St. Stephen Secondary School of the Cistercian Order. His favourite subject was chemistry. He engaged in his favourite sport, waterpolo for a long time; while the pastime he most enjoyed was playing the piano. As he had been interested in chemistry and biochemistry in all his youth, after leaving secondary school in 1948 he first applied to the Technical University of Budapest. However, his application was turned down 
due to his having attended a Catholic secondary school. For a year he did manual work in a material testing institution in order not to lose touch with chemistry, and also to be able to support his parents financially. For the second time he applied for admission to the Faculty of Sciences of Pázmány Péter University (from 1950 on, Eötvös Loránd University), and he was admitted as a student of biology and chemistry.

He attended Eötvös Loránd University of Budapest between 1949 and 1954; majoring in biology and chemistry at first. In 1952 biological research was introduced at the university as a degree subject, and he became one of the first students of this field of study. In 1954 he obtained a diploma as a certified botanist. He took up a job in the Botanical Department of the Hungarian Natural History Museum in Budapest. He worked there, under Bálint Zólyomi's directorship, mainly as a scientific researcher, but the museological and educational tasks he performed were significant as well. As a university student he was already deeply interested in questions related to the composition of vegetation, the distribution of plant communities and the regularities guiding this. He was still a university student when his first scientific articles were published on the alkali vegetation of the shores of Lake Velence and about the forests of the Velence Mountains. His first great floristical success was the discovery of Chlorocyperus glaber, a species hitherto unknown in the Hungarian flora. He later repeated this feat by discovering Stipa bromoides in the Bakony Mountains. He submitted an essay on his phytosociological research to a scientific competition at the university, and was awarded the first prize. He considered 1954 and 1955 as his real years of study, when he took part in the phytogeographical and coenological mapping of the Bükk Mountains. With Bálint Zólyomi's leadership, and the participation of the permanent members of the "Bükk Brigade": Pál Jakucs, Zoltán Baráth and András Horánszky, this was the fieldwork school that has had the greatest effect on Hungarian botany up to now. His first study trip abroad led him to Transylvania in 1956, which he walked all over, making botanical collections and phytosociological surveys in nearly all natural regions. It was also in 1956 that he first visited $\mathrm{Yu}-$ goslavia, where he studied the nature, origin and relationships of the sub-Mediterranean vegetation.

In 1959 he was awarded the doctoral degree. From the late 1950s onwards he engaged in intensive fieldwork in the Bakony Mountains. He mostly concerned himself with questions relating to forest vegetation, especially white oak scrub and high woodlands and Turkey oak-sessile oak forests. These induced him to extend his research to the vegetation of the 
Balkans. With this aim he took several study trips to Romania and Bulgaria in 1960 and 1961. He started to study the vegetation of the Gödölló Hills in 1960. He discovered the cool continental forest-steppe zone in Hungary, and described several of its plant communities. He defended his dissertation for the candidate's degree on this topic in 1965; in the same year he had a book published with the title "Die Waldvegetation im Gödöllöer Hügelland. Vergleichende pflanzengeographische Studie über die Wälder der kühl-kontinentalen Waldsteppe". To support his discoveries, he conducted research in Eastern Europe. After several unsuccessful attempts he was only able to realise his study trip to the Soviet Union in 1967.

He was among the first ones to discover the significance of spatial processes in the analysis of plant communities. In the 1970s his attention turned towards plant ecology. First he studied the role of life-forms in the functioning of plant communities, later he examined the spatial associations of population patterns. He showed that adaptation to light, the fixedness of light-photosynthesis curves may differ even within the same species. He was, even on a world scale, one of the first researchers who studied supraindividual pigment-homogeneity in terrestrial plant communities. One of the outstanding results of his reseach was ascertaining that photosynthetic structures are regulated also on the level of multi-species associations. The results of these researches are summed up in his academic doctoral dissertation, titled "Analysis of interspecific relationships, interactions and the ecological niche in oak-forest species" (1975). He became more and more interested in niche studies. He joined in the work of István Précsényi's research team engaged in the study of niches, and eventually in 1978 he took over the leadership of the team.

A new, ascendant stage of his career began in 1978, when - accepting Attila Borhidi's invitation - he became the scientific advisor of the Institute of Botany of the Hungarian Academy of Sciences, and set up the Department of Plant Ecology there. It was there that the long-term research projects on population dynamics were conducted that gave international acclaim to the work of Gábor Fekete and his research team, as well as to the results of their niche studies (1978-1990). He proved that certain population biological characteristics are regulated on the community level. He was able to show, with the help of exemplary, original research, that population dynamical reproductive allocation, which has demographic consequences, is influenced by interspecific competitive effects (1981). He started experimental studies aiming at a better understanding of the processes of degradation, which plays a decisive role in nature conservation 
(1983). He introduced ecophysiological methods into the practice of Hungarian fieldwork, thus highly increasing the international recognition of Hungarian ecological research (1985-86). He deserves credit for recognizing the need for the description of primary succession from a holistic point of view (1991-1992). He had a major part in the scientific investigations supporting the practice of nature conservation; first as the head of the research team that developed a strategy for the preservation of biodiversity (1993), then as the founder and promoter of Hungarian landscape ecological research (1996). He played a decisive role in the birth of three recently published books of prime importance, these are "Description and Identification Handbook of Hungarian Habitats and the General National Habitat Classification System" by G. Fekete, F. Horváth and Zs. Molnár (1997), "The Front Lines of Community Ecology", edited by Gábor Fekete (1998) and "Red Book of the Plant Communities in Hungary", edited by A. Borhidi and A. Sánta (1999).

Recently he has expended great effort to co-ordinate ecological research done in Hungary and to present it to an international public. The Symposium of Vácrátót of 1982, organized by him, was a milestone in the history of Hungarian vegetation research, and so was the book written based on the symposium: "The Questions of Coenological Succession", edited by Gábor Fekete (1985), which is one of the most important publications on syndynamic research in Hungary, both in theoretical and methodological respects. The following steps of this process were the First Hungarian Congress of Ecologists (1989), initiated and organized by him; the highly successful 34th International Symposium of the International Association of Vegetation Science (1991, Eger), at which he acted as chairman of the organizing committee; and the European Congress of Ecology, the EURECO '95 in Budapest, of which he was the president.

Gábor Fekete is a master of scientific work endowed with outstanding efficiency. As the head of a research team or department of an institute, he has had a greater influence on the formation of the new generation of ecologists than the majority of the professors of this field. He made remarkable contributions to researcher education by founding a new school. The author of these lines is particularly grateful for the inestimable formative and educational activity that he has done and still carries on today, within the framework of the Vegetation Research Programme of the Botanical Doctoral School of the University of Pécs. There is no ecologist under the age of 60 in Hungary today who has learnt nothing from him. The educational and formative work he has done in bringing up generations of gifted and 
successful ecologists is of immense significance in the present and future of Hungarian science. The success of this work has been demonstrated by many talented, internationally acknowledged researchers. Young people in search of a suitable profession or just starting a career often go to him for advice; moreover, renowned colleagues turn to him with equal confidence with professional, and not infrequently personal problems.

It is a proof of his enormous capacity for work and his thorough scientific grounding that besides his high-standard research work he has been a member of more than twenty Hungarian and international scientific committees, organizations and editorial boards, holding key offices in several of them. He also edited Acta Botanica Hungarica for several years.

As a recognition of his scientific achievements, he was elected corresponding member of the Hungarian Academy of Sciences in 1987, and ordinary member in 1995. In 1999 he received the Széchenyi prize, the highest honour given for scientific work.

On his seventieth birthday, the editorial board of Acta Botanica Hungarica, together with the whole society of Hungarian botanists and ecologists, wish Gábor Fekete, the friend, colleague, master and teacher, a long, happy and fruitful life.

\section{BIBLIOGRAPHY OF G. FEKETE}

Fekete, G. (1954): A Chlorocyperus glaber (L.) Palla Magyarországon. - Bot. Közlem. 45: 253-254.

Fekete, G. (1955): Die Vegetation des Velenceer Gebirges. - Annls hist.-nat. Mus. natn. Hung. 7: 343-362.

Jakucs, P. \& Fekete, G. (1956): A magyarországi molyhos-tölgyes karsztbokorerdók monográfikus feldolgozásának előmunkálatai. - Az I. Biol. vándorgyúlés előadásainak ismertetése, MBT, Budapest, p. 62.

Jakucs, P. \& Fekete, G. (1957): Preliminaries to a monograph of the karstic hair oak bush forest in Hungary. - Proceedings of the first meeting of the Hungarian Biological Society. Acta Biol. Hung. 7 Suppl. 1: 43.

Jakucs, P. \& Fekete, G. (1957): Der Karstbuschwald des nordöstlichen ungarischen Mittelgebirges. - Acta Bot. Hung. 3: 253-259.

Fekete, G. \& Jakucs, P. (1957): Néhány karsztbokorerdő-faj elterjedési adatainak katalógusa Magyarországról. - Annls hist.-nat. Mus. natn. Hung. 8: 181-195.

Jakucs, P. \& Fekete, G. (1958): Összehasonlító növényföldrajzi tanulmányúton Jugoszláviában. - Földrajzi Közlem. 6(82): 286-292.

Fekete, G. \& Jakucs, P. (1959): A növényföldrajzi kutatás helyzete Jugoszláviában. - MTA Biol. Csop. Közlem. 3: 109-113.

Jakucs, P., Fekete, G. \& Gergely, J. (1959): Angaben zur Vegetation der Moldau und der Dobrudscha. - Annls hist.-nat. Mus. natn. Hung. 51: 211-225. 
Fekete, G. (1959): Angaben zur Zönologie der moesischen Schwarzföhrenwälder. - Acta Bot. Hung. 5: 327-347.

Fekete, G. (1959): Stipa bromoides (L.) Dörfl., eine neuentdeckte Pflanze in Ungarn. - Acta Bot. Hung. 5: 349-356.

Fekete, G. (1961): Les groupements forestiers a arbres feuillus des forests steppes fraiches-continentales en Hongrie. - Acta Bot. Hung. 7: 229-233.

Fekete, G., Majer, A., Tallós, P., Vida, G. \& Zólyomi, B. (1961): Angaben und Bemerkungen zur Flora und zur Pflanzengeographie des Bakonygebirges. - Annls hist.-nat. Mus. natn. Hung. 53: 241-253.

Fekete, G. (1961): Erdőtanulmányok a Gödöllői Dombvidéken. - Bot. Közlem. 49: 132.

Fekete, G. \& Járai-Komlódi, M. (1962): Die Schuttabhangwälder der Gerecse- und Bakony-Gebirge. - Ann. Univ. Sci. Budapest., Sect. Biol. 5: 115-129.

Fekete, G. (1963): Die Schluchtwälder des Bakony-Gebirges II. - Annls hist.-nat. Mus. natn. Hung. 55: 215-231.

Fekete, G. (1963): Verbreitungspunktkarte der Pflanzenarten des Bakony-Gebirges. I. Charakterarten der Schluchtwälder. - Fragmenta Botanica 3: 97-107.

Fekete, G. (1964): A Bakony növénytakarója. A Bakony cönológiai-növényföldrajzi képe. - A Bakony természettudományos kutatásának eredményei. I., Veszprém, 40 pp.

Fekete, G. (1965): Erdővegetáció-tanulmányok a Gödöllői dombvidéken. A hüvöskontinentális erdőssztyep erdőinek összehasonlitó növényföldrajzi vizsgálata. - Kandidátusi értekezés tézisei, Budapest, 8 pp.

Fekete, G. (1965): Die Waldvegetation im Gödöllőer Hügelland. Vergleichende pflanzengeographische Studie über die Wälder der kühl-kontinentalen Waldsteppe. - Akadémiai Kiadó, Budapest, 223 pp.

Fekete, G. \& Zólyomi, B. (1966): Über die Vegetationszonen und pflanzengeographische Charakteristik des Bakony-Gebirges. - Annls hist.-nat. Mus. natn. Hung. 58: 197-205.

Fekete, G. (1966): Der xerotherme Flaumeichen-Buschwald des nördlichen Bakony-Gebirges. Die Phytozönosen des Bakony-Gebirges. III. - Annls hist.-nat. Mus. natn. Hung. 58: 207-221.

Fekete, G. (1967): Der Wallnuss-Baumhasel-Felsenwald der Berge von Oltenien. - Annls hist.-nat. Mus. natn. Hung. 59: 163-173.

Zólyomi, B., Baráth, Z., Fekete, G., Jakucs, P., Kárpáti, I., Kárpáti, V., Kovács, M. \& Máthé, I. (1967): Einreihung von 1400 Arten der ungarischen Flora in ökologische Gruppen nach TWR-Zahlen. - Fragmenta Botanica 4: 101-142.

Fekete, G. (1967): Corno-Quercetum. - In: Zólyomi, B. (ed.): Guide der Excursionen des Internationalen Geobotanischen Symposiums, Eger-Vácrátót, pp. 38-40.

Précsényi, I., Fekete, G. \& Szujkó-Lacza, J. (1967): Pattern studies in Quercus pubescens wood. - Acta Bot. Hung. 13: 277-298.

Szujkó-Lacza, J., Fekete, G. \& Kováts, D. (1968): The role in population dynamics, and the importance in production studies of the vegetative propagation mechanisms of plants. - 8th meeting of the Hungarian Biological Society. Acta Biol. Hung. 19: 526-527.

Fekete, G. \& Szujkó-Lacza, J. (1968): Vengersko-Sovietskie sviazi v oblasti botaniki. Rodstvo rastitel, nosti na territorii Vostocnoj Evropy I pannonijskoj flory. - Annls hist.-nat. Mus. natn. Hung. 60: 349-360.

Fekete, G. \& Jakucs, P. (1968): Der xerotherme Eichenwald des Bükk-Gebirges (CornoQuercetum). (A Bükk hegység xerotherm tölgyerdője (Corno-Quercetum)). - Bot. Közlem. 55: 59-68. 
Szujkó-Lacza, J. \& Fekete, G. (1969): A survey of the plant life-form systems and the respective research approaches. I. - Annls hist.-nat. Mus. natn. Hung. 61: 129-139.

Szujkó-Lacza, J. \& Fekete, G. (1969): Jelentősebb növényi életforma-rendszerek és kutatási irányzatok. I. - Bot. Közlem. 56: 177-180.

Fekete, G. \& Szujkó-Lacza, J. (1970): Jelentősebb növényi életforma-rendszerek és kutatási irányzatok. II. - Bot. Közlem. 57: 245-249.

Fekete, G. \& Szujkó-Lacza, J. (1970): A survey of the plant life-form systems and the respective research approaches. II. - Annls hist.-nat. Mus. natn. Hung. 62: 115-127.

Szujkó-Lacza, J., Fekete, G. \& Faludi-Dániel, Á. (1970): Contribution to the conditions of photosynthetic activity of lignifying shoot axes. - Acta Bot. Hung. 16: 398-404.

Szujkó-Lacza, J., N. Rakován, J. \& Fekete, G. (1970): A fásodó hajtások fotoszintetikus tevékenysége és ennek erdészeti jelentősége. - Erdőgazdaság és Faipar 12: 13-14.

Fekete, G. \& Szujkó-Lacza, J. (1971): A survey of the plant life-form systems and the respective research approaches. III. - Annls hist.-nat. Mus. natn. Hung. 63: 37-50.

Szujkó-Lacza, J. \& Fekete, G. (1971): The correlation of species and habitat factors in a xerothermic oak forest (Orno-Quercetum) stand. - Feddes Repertorium 82: 263-286.

Szujkó-Lacza, J., N. Rakován, J., Horváth, G. \& Fekete, G. (1971): Anatomical, ultrastructural and physiological studies on one-year old Euonymus europaeus bark displaying photosynthetic activity. - Acta Agr. Hung. 20: 247-260.

Szujkó-Lacza, J. \& Fekete, G. (1972): A survey of the plant life-form systems and the respective research approaches. IV. - Ann. hist.-nat. Mus. natn. Hung. 64: 54-62.

Szujkó-Lacza, J., N. Rakován, J., Fekete, G. \& Horváth, G. (1972): Anatomical, ultrastructural and physiological studies on the primary cortex of Euonymus europaeus L. displaying photosynthetic activity. II. - Acta Agr. Hung. 21: 41-56.

Fekete, G. (1972): A növénytársulás fiziognómiai struktúrája, a fény és a víz mint produkcióökológiai tényezők. - MTA Biol. Oszt. Közlem. 15: 137-158.

Fekete, G. \& Szujkó-Lacza, J. (1973): Leaf anatomical and photosynthetical reactions of Quercus pubescens Willd. to environmental factors in various ecosystems. I. Leaf anatomical reactions. - Acta Bot. Hung. 18: 59-89.

Fekete, G., Szujkó-Lacza, J. \& Horváth, G. (1973): Leaf anatomical and photosynthetical reactions of Quercus pubescens Willd. to environmental factors in various ecosystems. II. Photosynthetic activity. - Acta Bot. Hung. 18: 281-293.

Fekete, G. \& Szujkó-Lacza, J. (1973): Interspecific correlation of plants in oakwood at increasing block sizes. - Acta Biol. Hung. 24: 31-42.

Szujkó-Lacza, J. \& Fekete, G. (1973): Synphenological changes in the vegetation of a submediterranean oak forest (Orno-Quercetum). - Annls hist.-nat. Mus. natn. Hung. 63: 127-146.

Fekete, G. (1973): A CO 2 koncentráció napi menetei tölgyesek légterében. - Bot. Közlem. 60: 43-48.

Fekete, G. \& Priszter, Sz. (1973): A balkáni flóra és vegetáció első nemzetközi szimpóziuma, Várna, (1973 június 7-10). - Bot. Közlem. 60: 211-212.

Fekete, G. \& Szőcs, Z. (1974): Studies on interspecific association processes in space. - Acta Bot. Hung. 20: 227-241.

Szujkó-Lacza, J. \& Fekete, G. (1974): Examination of development and growth of Brachypodium silvaticum and Euphorbia cyparissias in oakwoods. - Acta Bot. Hung. 20: 147-158.

Fekete, G. (1974): Tölgyesek relatív megvilágítása és gyepszint-fajainak eloszlása. - Studia Bot. Hung. 9: 87-96. 
Fekete, G. (1974): Átültetési kísérletek Polygonatum odoratum ökotípusokkal különböző fénykörnyezetekben. I. A fény-fotoszintézis görbék módosulása. - Bot. Közlem. 61: 199-204.

Fekete, G. \& Kováts, D. (1974): A 100 éves Növénytár herbáriumainak története. II. Herbarium Carpato-Pannonicum. - Bot. Közlem. 61: 223-228.

Fekete, G. (1975): Aerial environment and tolerance of Polygonatum odoratum (Mill.) Druce in natural communities. - Acta Agr. Hung. 24: 89-97.

Fekete, G. (1975): Átültetési kísérletek Polygonatum odoratum ökotípusokkal különböző fénykörnyezetekben. II. A növekedési paraméterek módosulása. - Bot. Közlem. 62: 29-31.

Fekete, G. (1975): Interspecifikus kapcsolatok, kölcsönhatások és az ökológiai niche elemzése tölgyerdei fajokon. - Doktori értekezés tézisei, 14 pp.

Draskovits, R. \& Fekete, G. (1976): Chlorophyll concentration and its ecological significance in some species in beechwoods. - Acta Bot. Hung. 22: 29-38.

Fekete, G., Précsényi, I., Molnár, E. \& Melkó, E. (1976): Niche studies on some plant species of a grassland community. I. Comparison of various measurements. - Acta Bot. Hung. 22: 321-354.

Fekete, G. \& Tuba, Z. (1977): Supraindividual versus individual homogeneity of photosynthetic pigments: a study on community structure. - Acta Bot. Hung. 23: 319-331.

Précsényi, I., Fekete, G., Melkó, E. \& Molnár, E. (1977): Niche studies on some plant species of a grassland community. II. Seasonal niche dynamics. - Acta Bot. Hung. 23: 193-218.

Précsényi, I., Fekete, G., Melkó, E. \& Molnár, E. (1977): Niche studies on some plant species of a grassland community. III. Overlap investigations by cluster analysis. - Acta Bot. Hung. 23: 369-374.

Fekete, G. \& Kovács, M. (1978): The space dynamism of species- and life-form diversity in two rocky grassland communities. - Acta Biol. Debrecina 15: 7-21.

Fekete, G., Précsényi, I., Horánszky, A. \& Tölgyesi, Gy. (1979): Niche studies on some plant species of a grassland community. IV. Niche characteristic of Festuca vaginata populations on the basis of the macro- and microelement content of the soil and the plant. Acta Bot. Hung. 25: 63-73.

Précsényi, I., Fekete, G., Molnár, E., Melkó, E. \& Virágh, K. (1979): Niche studies on some plant species of a grassland community. V. Arrangement of species in the three dimensional niche space. - Acta Bot. Hung. 25: 131-138.

Tölgyesi, Gy., Fekete, G., Précsényi, I. \& Horánszky, A. (1979): Ökológiai és módszertani megfigyelések homokpuszták talajának és növényzetének elemi összetételével kapcsolatban. - Agrokémia és Talajan 28: 97-114.

Fekete, G. (1980): Die Vegetationskartierung in Ungarn. - Folia Geobot. Phytotax. 15: 193-196.

Fekete, G. (1980): Lucos ökoszisztémák stabilitása. MAB-IUFRO szimpózium, Brünn. - Bot. Közlem. 67: 62-64.

Fekete, G., Précsényi, I., Molnár, E. \& Nosek, N. J. (1980): Szerkezet és múködés egy természetes növénytársulásban. Eredmények, problémák és perspektívák a Tecehomokpusztagyep kutatásában. - MTA Biol. Oszt. Közlem. 22: 311-322.

Précsényi, I., Fekete, G., Molnár, E., Melkó, E. \& Virágh, K. (1980): Niche studies on some plant species of a grassland community. VI. The problem of ecological specialism and generalism: new approaches. - Acta Bot. Hung. 26: 417-424.

Fekete, G., Tuba, Z. \& Précsényi, I. (1980): Niche studies on some plant species of a grassland community VII. Quantity and seasonality of photosynthetic pigments. - Acta Bot. Hung. 26: 289-297. 
Barcsák, Z., Czimber, Gy., Fekete, G. \& Láng, E. K. (1981): MAB 3 Project. Survey of 10 years activity in Hungary. - In: Stefanovits, P., Berczik, Á., Fekete, G. \& Seidl, M. (eds): MAB Programme. Survey of 10 years activity in Hungary. pp. 49-66.

Fekete, G. \& Précsényi, I. (1981): Niche structure of a perennial sandy grassland. - In: Stefanovits, P., Berczik, Á., Fekete, G. \& Seidl, M. (eds): MAB Programme. Survey of 10 years activity in Hungary. pp. 67-102.

Borhidi, A., Fekete, G., Katona, S., Kovács, M., Pécsi, M. \& Várkonyi, T. (1981): Qualification of the urban environment and some aspects of air pollution in the Budapest Agglomeration. In: Stefanovits, P., Berczik, Á., Fekete, G. \& Seidl, M. (eds): MAB Programme. Survey of 10 years activity in Hungary. pp. 353-413.

Fekete, G. (1981): Természetes erdők, mesterséges állományok. Bevezető. - Bot. Közlem. 68: 133.

Fekete, G. (1981): A növényi populációk. Az ökológiai niche. A fény. A víz. Életformák, biológiai típusok. Ökológiai fajcsoportok. - In: Hortobágyi, T. \& Simon, T. (szerk.): Növényföldrajz, -társulástan, -ökológia. Tankönyvkiadó, Budapest, pp. 169-191, pp. 274-280, pp. 280-300, pp. 317-335, pp. 373-380, pp. 416-417.

Fekete, G. \& Melkó, E. (1981): Reproductive allocation in the stages of sandy succession. Acta Bot. Hung. 27: 351-364.

Fekete, G. \& Virágh, K. (1982): Vegetációdinamikai kutatások és a gyepek degradációja. MTA Biol. Oszt. Közlem. 25: 415-420.

Fekete, G. \& Kovács, M. (1982): A Fóti Somlyó vegetációja. - Bot. Közlem. 69: 19-31.

Fekete, G. \& Tuba, Z. (1982): Photosynthetic activity in the stages of sandy succession. - Acta Bot. Hung. 28: 291-296.

Szujkó-Lacza, J., Fekete, G., Kováts, D., Szabó, L. \& Siroki, Z. (1982): The vascular plants of the Hortobágy National Park. - In: Szujkó-Lacza, J. (ed.): The flora of the Hortobágy National Park. Akadémiai Kiadó, Budapest, pp. 105-169.

Virágh, K. \& Fekete, G. (1983): Herbicidekkel előidézett degradáció legelő növényzetének struktúrájában. - Agrokémia és Talajtan 32: 554-559.

Virágh, K. \& Fekete, G. (1984): Degradation stages in a xeroseries: composition, similarity, grouping, coordination. - Acta Bot. Hung. 30: 427-459.

Fekete, G. (1985): A terresztris vegetáció szukcessziója: elméletek, modellek, valóság. - In: Fekete, G. (szerk.): A cönológiai szukcesszió kérdései. Akadémiai Kiadó, Budapest, pp. 31-63.

Fekete, G. (1985): Zárszó. - In: Fekete, G. (szerk.): A cönológiai szukcesszió kérdései. Akadémiai Kiadó, Budapest, pp. 211-216.

Tuba, Z. \& Fekete, G. (1985): Ökofiziológia és ökológia. - Előadás- és poszterkivonatok, II. Magyar Növényélettani Kongresszus, Szeged, p. 284.

Tuba, Z. \& Fekete, G. (1986): Ökofiziológia és ökológia. Alapvetések, valamint példák a faji-populációs és társulásszintû megközelítésekre. - Bot. Közlem. 73: 197-204.

Fekete, G. (1987): Növényföldrajzi vizsgálatok. - In: Ádám, L., Marosi, S. \& Szilárd, J. (szerk.): A Dunántúli Középhegység A. Akadémiai Kiadó, Budapest, pp. 36-37.

Jakucs, P. \& Fekete, G. (1987): Természetes növénytakaró. - In: Ádám, L., Marosi, S. \& Szilárd, J. (szerk.): A Dunántúli Középhegység A. Akadémiai Kiadó, Budapest, pp. 337-353.

Fekete, G., Virágh, K. \& Horánszky, A. (1987): Facies and their responses to pertubation in a turkey oak-sessile oak wood. - Acta Bot. Hung. 33: 19-40.

Fekete, G., Tuba, Z. \& Melkó, E. (1987): Background processes on population level in the course of succession. - Abstracts, XIV. International Botanical Congress, Berlin West, p. 364.

Précsényi, I. \& Fekete, G. (1987): Niche-tanulmányok homokpusztagyepben:áttekintés. - In: Halmágyi, L. (szerk.): A niche problémaköre. A Biológus Disputa előadásai, Eger, pp. 5-9. 
Fekete, G., Tuba, Z. \& Melkó, E. (1988): Background processes at the population level during succession in grassland on sand. - Vegetatio 77: 33-41.

Szegi, J., Oláh, J., Fekete, G., Halász, T., Várallyay, Gy. \& Bartha, S. (1988): Recultivation of the spoil banks created by open-cut mining activities in Hungary. - Ambio 17: 137-143.

Fekete, G. (1988): Az I. Magyar Ökológus Kongresszus. - Magyar Tudomány 33: 973-980.

Fekete, G. (1988): Ecology and syndynamics of the Pannonian sandy grasslands. - Abstracts, 2nd Symposium on Botany, Cuba, La Habana, p. 185.

Fekete, G. (1988): Természetes növénytakaró (Bakonyvidék). - In: Ádám, L., Marosi, S. \& Szilárd, J. (szerk.): A Dunántúli Középhegység B. Akadémiai Kiadó, Budapest, pp. 149-174.

Fekete, G. (1988): Növényzet (Vértes-Velencei hegyvidék). - In: Ádám, L., Marosi, S. \& Szilárd, J. (szerk.): A Dunántúli Középhegység B. Akadémiai Kiadó, Budapest, pp. 286-297.

Fekete, G. (1988): Természetes növényzet (Dunazúg hegység). - In: Ádám, L., Marosi, S. \& Szilárd, J. (szerk.): A Dunántúli Középhegység B. Akadémiai Kiadó, Budapest, pp. 420-430.

Fekete, G. (1988): Sixty years activity of Prof. Bálint Zólyomi in the field of plant ecology.Acta Bot. Hung. 34: 3-9.

Fekete, G. (1989): Zólyomi Bálint nyolcvanéves. - Földr. Közlem. 37: 277-277.

Fekete, G., Tölgyesi, Gy. \& Horánszky, A. (1989): Dolomite versus limestone habitats: a study of ionic accumulation on a broader floristic basis. - Flora 183: 337-348.

Fekete, G., Virágh, K. \& Horánszky, A. (1989): The effect of perturbation on the composition of a Pannonian oak forest. - Studies in Plant Ecology (Uppsala) 18: 76-78.

Fekete, G. (1990): Welcome address. - In: Bíró, P. \& Talling, J. F. (eds): Trophic relationships in inland waters. Kluwer, Dordrecht-Boston-London, Hydrobiologia (191). pp. XV-XVI.

Fekete, G., Tuba, Z. \& Précsényi, I. (1990): Niche space partition in a sandy grassland: parallel approaches for describing populations. - Abstracts, V. INTECOL, Yokohama, p. 46.

Fekete, G. (1990): Razvitie i osznovnüe napravlenija ekologicseszkih isszledovanij $v$ Vengrii. Problemü Ekologii, Petrozavodszk, pp. 113-120.

Fekete, G. (1990): Ökológiai kutatások. A hazai biológiai kutatások koncepciója az 1990-es években. - Magyar Tudomány pp. 1165-1170.

Fekete, G. (1991): Dynamic analysis of coalitions and guilds. - In: Advances in biological research in Hungary, 1986-1990, pp. 23-25.

Fekete, G. (1991): The holistic approach of succession reconsidered. - Abstracts, 34th International Symposium of IAVS, Eger, p. 4.

Fekete, G. (1991): Holizmus vagy redukcionizmus: vegetációdinamikai változatok. - Abstracts, II. Magyar Ökológus Kongresszus, Keszthely, p. 41.

Simon, T., Fekete, G. \& Török, K. (1992): Phytosociology in establishing, monitoring and reconstruction of nature reserves in Hungary. - Abstracts, 35th International Symposium of IAVS, Shanghai, pp. 153-155.

Fekete, G. (1992): The holistic view of succession reconsidered. - Coenoses 7: 21-29.

Fekete, G. \& Tóthmérész, B. (1993): Vegetation Science in Hungary. - J. Vegetation Science 4: 279-282.

Kovácsné Láng, E. \& Fekete, G. (1993): Hungary. - In: Proceedings of an international summit, International networking in long term ecological researches, Estes Park, Colorado, USA, pp. 59-60.

Zólyomi, B., Fekete, G. \& Virágh, K. (1993): Relic vegetation islands in the Hungarian Mountain Range: their origin, composition and hazard of vanishing. - Abstracts, 36th Symposium of IAVS, Santa Cruz de Tenerife, p. 57. 
Bartha, S., Csapody, I., Dános, B., Fekete, G., Gallé, L., Holly, L., Horváth, F., Jenser, G., Kereszty, Z., Kovács, Gy., Németh, F., Papp, L., Simon, T., Surányi, D., Szabó, T. A., Szőcs, Z. \& Varga, Z. (1993): Nemzeti biodiverzitás-megőrzési stratégia. - Magyar Tudomány pp. 983-1010.

Fekete, G. (1993): Preface. - In: Szujkó-Lacza, J. \& Kováts, D. (eds): The flora of the Kiskunság National Park. Magyar Természettudományi Múzeum, Budapest, pp. 7-8.

Nagy, Z., Tuba, Z., Szenthe, K., Uzvölgyi, J. \& Fekete, G. (1994): Photosynthesis and water use efficiency during degradation of a semiarid loess steppe. - Photosynthetica 30: 307-311.

Zólyomi, B. \& Fekete, G. (1994): The Pannonian loess steppe: differentiation in space and time. - Abstracta Botanica 18: 29-41.

Nagy, Z., Szente, K., Tuba, Z. \& Fekete, G. (1994): A löszgyep degradáció és az ennek során fellépő Bothriochloa ischaemum invázió ökofiziológiai okairól. - Abstracts, III. Magyar Ökologus Kongresszus, Szeged, p. 131.

Hochstrasser, T., Bartha, S. \& Fekete, G. (1994): Structural changes in a loess grassland due to Bothriochloa invasion. - Abstracts, III. Magyar Ökológus Kongresszus, Szeged, p. 119.

Bartha, S., Csapody, I., Dános, B., Fekete, G., Gallé, L., Holly, L., Horváth, F., Jenser, G., Kereszty, Z., Kovács, Gy., Németh, F., Papp, L., Simon, T., Surányi, D., Szabó, A. T., Szőcs, Z. \& Varga, Z. (1994): Foundations for developing a national strategy of biodiversity conservation. - Acta Zool. Hung. 40: 289-327.

Borhidi, A., Dévay, Gy., Fekete, G., Kerényi, A., Tardy, J. \& Varga, Z. (1994): Nemzeti Természetpolitikai Koncepció. - Természetvédelem 94: 7-42.

Kovácsné Láng, E. \& Fekete, G. (1995): Miért kellenek hosszú távú ökológiai kutatások? Magyar Tudomány 40: 377-392.

Fekete, G., Tuba, Z. \& Précsényi, I. (1995): Application of three approaches to evaluate abundance and rarity in a sand grassland community. - Coenoses 10: 29-38.

Fekete, G. (1995): Message from the President of EURECO '95. - Ecology in Hungary, Budapest, pp. 7-8.

Rédei, T., Kovács-Láng, E., Fekete, G., Moskát, Cs., Horváth, F., Tarján, P., Báldi, A., Fuisz, T., Kisbenedek, T., Németh, L. \& Molnár, A. (1995): CORINE Biotopes Project in Hungary. - Abstracts, 7th EURECO, Budapest, p. 135.

Kovács-Láng, E., Fekete, G., Bartha, S., Molnár, E., Hahn, I. \& Standovár, T. (1995): Coenological and soil processes in loess grassland degradation. - Abstracts, 7th EURECO, Budapest, p. 175.

Hochstrasser, T., Bartha, S. \& Fekete, G. (1995): The structure of different loess grassland types. Abstracts, 7th EURECO, Budapest, p. 238.

Fekete, G. (1995): Előszó. - In: 125 éves a Magyar Természettudományi Múzeum Növénytára. Magyar Természettudományi Múzeum, Budapest, pp. 5-6.

Tuba, Z., Csintalan, Zs., Szente, K., Nagy, Z., Lichtenthaler, H. K., Maróti, I., Grace, J., Proctor, M. C. F., Smirnoff, N., Masarovicova, E., Laitat, E., Takács, Z., Kemény, G., Badacsonyi, A., Pócs, T. \& Fekete, G. (1995-96): Desiccation and revival of desiccation tolerant plants at present and elevated CO2. - Bull. Univ. Agric. Sci., Gödöllő, 75th Anniversary Edition, pp. 83-91.

Szente, K, Nagy, Z., Tuba, Z. \& Fekete, G. (1996): Photosynthesis of Festuca rupicola and Bothriochloa ischaemum under degradation and cutting pressure in a semiarid loess grassland. - Photosynthetica 32: 399-407.

Borhidi, A., Dévay, Gy., Fekete, G., Kerényi, A., Tardy, J. \& Varga, Z. (1996): Priorities of the Hungarian natural policy in nature preservation. - In: Halasi-Kun, G. (ed.): Environmen- 
tal problems and possible solutions in the Carpathian Basin. Pollution and water resources. Columbia University seminal series 28, 1994, pp. 7-46.

Fekete, G. (1996): A hazai biodiverzitás: feltárás, megértés, megőrzés. - Természet Világa 127(2)(különszám): 16-19.

Fekete, G., Virágh, K. \& Aszalós, R. (1996): Landscape pattern and community differentiation.Abstracts, 39th IAVS Symposium, Lancaster, p. 20.

Fekete, G. \& Virágh, K. (1997): Félszáraz Brachypodium pinnatum gyepek kompozíciós differenciációja. - Kitaibelia 2: 276.

Borhidi, A. \& Fekete, G. (1997): Quo vadis, magyar ökológia? - TermészetBÚVÁR 52(5): $10-12$.

Fekete, G., Horváth, F., Molnár, Zs. \& Kovács-Láng, E. (1997): Lessons from the development of a national biodiversity monitoring program. - Abstracts, Annual Meeting, Bull. Ecol. Soc. Amer., Suppl., p. 246.

Fekete, G., Virágh, K. \& Aszalós, R. (1997): Tájmintázat és társulásdifferenciáció: egy esettanulmány. - Abstract kötet, IV. Magyar Ökológus Kongresszus, Pécs, p. 62.

Bartha, S., Bódis, J., Fekete, G., Hochstrasser, T., Ittzés, P., Kertész, M., Kun, A., Mucina, L., Oborny, B., Rédei, T., Szollát, Gy. \& Virágh, K. (1997): Száraz gyepek térbeli szerveződésének összehasonlító vizsgálata Juhász-Nagy Pál modellcsaládjával. - Abstract kötet, IV. Magyar Ökológus Kongresszus, Pécs, p. 30.

Fekete, G. (1997): Welcome by the President of EURECO '95. - Abstracta Botanica 21: 217.

Fekete, G. (1997): Zólyomi Bálint (1908-1997) in the history of (Hungarian) plant ecology. Collecta Clusiana 7(12): 5-11.

Fekete, G., Molnár, Zs. \& Horváth, F. (szerk.) (1997): A Nemzeti Biodiverzitás-monitorozó Rendszer II. A magyarországi élőhelyek leírása, határozója és a Nemzeti Élőhely-osztályozási Rendszer. - Magyar Természettudományi Múzeum, Budapest.

Fekete, G. (1998): Javaslat új típusú vegetációmonográfiák megalkotásához. - Kitaibelia 3: 71-73.

Fekete, G. (1998): Az “Aktuális flóra- és vegetációkutatások Magyarországon” c. konferencia megnyitója. - Kitaibelia 3: 45-46.

Fekete, G. (1998): Zólyomi Bálint (1908-1997). - Magyar Tudomány 1998: 93-95.

Fekete, G. (1998): Fitocönológia és vegetációtan: hazai aszpektusok. - Bot. Közlem. 82(1995): 107-127.

Fekete, G., Virágh, K., Aszalós, R. \& Orlóci, L. (1998): Landscape and coenological differentiation in Brachypodium pinnatum grassland. - Coenoses 13: 39-53.

Bartha, S., Fekete, G., Molnár, E., Virágh, K. Oborny, B. \& Mucina, L. (1998): Funkciós csoportok térbeli szerveződése löszgyepekben. - Kitaibelia 3: 315-316.

Fekete, G. \& Fekete, Z. (1998): Distance distribution between patch systems: a new method to analyse community mosaics. - Abstracta Botanica 22: 1-7.

Jermy, T., Borhidi, A., Fekete, G. \& Kovács-Láng, E. (1998): Egy kelet-közép-európai ökológiai kutatóhálózat érdekében. - Ezredforduló, stratégiai kutatások a Magyar Tudományos Akadémián, 4: 34-36.

Virágh, K. \& Fekete, G. (1998): Vegetation pattern and coenological differentiation of a xeromesophilous grassland community: a case study. - Proceedings, 7th INTECOL, Florence, Italy.

Fekete, G. (1998): Előszó. - In: Csontos, P. (szerk.): Sziklagyepek szünbotanikai kutatása. Zólyomi Bálint professzor emlékének. Scientia, Budapest, pp. 11-12.

Fekete, G. (szerk.) (1998): A közösségi ökológia frontvonalai. - Scientia, Budapest, 233 pp. 
Kovács-Láng, E., Fekete, G. \& Molnár, Zs. (1998): Mintázat, folyamat, skála: hosszú távú ökológiai kutatások a Kiskunságban. - In: Fekete, G. (szerk.): A közösségi ökológia frontvonalai. Scientia, Budapest, pp. 209-224.

Fekete, G. (1998): Utószó. - In: Fekete, G. (szerk.): A közösségi ökológia frontvonalai. Scientia, Budapest, pp. 225-233.

Jakucs, P., Fekete, G., Járainé Komlódi, M., Somogyi, S. \& Kéri, M. (1999): Zólyomi Bálint (1908-1997). - Emlékbeszédek az MTA elhunyt tagjai felett. MTA, Budapest, 28 pp.

Fekete, G. (1999): Cserszömörcés karsztbokorerdő (FG-VZ, 2: 240-242). Szubkontinentális tölgyesek és elegyes xerotherm erdők (FG-VZ, 2: 258-259). Andezit törmeléklejtő tölgyese (FG, 2: 259-260); Hársas-kőrises sziklaerdő (FG-VZ, 2: 260-262). Melegkedvelő tölgyes (FG-VZ, 2: 263-265). Sajmeggyes bokorerdő (FG-VZ, 2: 266-269). Gyöngyvirágos tölgyesek (FG-VZ, 2: 269-272). Nyáras-borókás (FG, 2: 273-276); Nyírségi pusztai tölgyes (FG-BA-VZ, 2: 276-279). Gyertyánelegyes mezei juharos tölgyes (FG, 2: 279-280). Hársas-tölgyes (FG, 2: 280-282). Tatárjuharos lösztölgyes (FG-VZ, 2: 282-285). Sziki tölgyes (FG, 2: 286-288). - In: Borhidi, A. \& Sánta, A. (szerk.): Vörös könyv Magyarország növénytársulásairól. TermészetBúvár Alapítvány Kiadó.

Fekete, G., Molnár, Zs., Kun, A. \& Botta-Dukát, Z. (1999): Landscape dependence of steppe grasslands along a climatic gradient. - Abstracts, 42nd Annual Symposium of the IAVS, p. 53.

Fekete, G., Kun, A. \& Molnár, Zs. (1999): Floristic characteristics of the forest-steppe in the Danube-Tisza Interfluve. - In: Kovács-Láng, E., Molnár, E., Kröel-Dulay, Gy. \& Barabás, S. (eds): Long Term Ecological Research in the Kiskunság, Hungary. Institute of Ecology and Botany of the HAS, Vácrátót, pp. 13-14.

Fekete, G. (1999): Dynamic relationship of primary vegetation types on sand. - In: Kovács-Láng, E., Molnár, E., Kröel-Dulay, Gy. \& Barabás, S. (eds): Long Term Ecological Research in the Kiskunság, Hungary. Institute of Ecology and Botany of the HAS, Vácrátót, pp. 14-15.

Fekete, G. \& Précsényi, I. (1999): The niche structure of the open sand grassland. - In: KovácsLáng, E., Molnár, E., Kröel-Dulay, Gy. \& Barabás, S. (eds): Long Term Ecological Research in the Kiskunság, Hungary. Institute of Ecology and Botany of the HAS, Vácrátót, pp. 38-39.

Fekete, G. (1999): Botanika, erdészet, természetvédelem. - Kitaibelia 4: 347-355.

Fekete, G., Kun, A. \& Molnár, Zs. (1999): Chorológiai grádiensek a Duna-Tisza közi erdei flórában. - Kitaibelia 4: 343-346.

Fekete, G. (1999): Vegetációtérképezés: visszatekintés és hazai körkép. - Bot. Közlem. 85 (1998): 17-30.

Fekete, G. (1999): A vegetációtérképezés: visszatekintés és hazai körkép. - In: Kun, A. \& Molnár, Zs. (szerk.): Élőhelytérképezés (Nemzeti Biodiverzitás-monitorozó Rendszer XI.), pp. 91-104.

Fekete, G., Virágh, K., Aszalós, R. \& Précsényi, I. (2000): Landscape-level heterogeneity: static and dynamic approaches. - J. Vegetation Science 11: 375-382.

Kovács-Láng, E., Fekete, G., Horváth, F., Molnár, Zs., Török, K., Tardy, J. \& Demeter, A. (2000): Development and implementation of a National Biodiversity Monitoring Programme in Hungary. - In: Bischoff, C. \& Dröschmeister, R. (eds): European Monitoring for Nature Conservation. Bonn (Bundesamt für Naturschutz), Schriftenr. F. Landschaftspflege u. Naturschutz 62: 59-68.

Fekete, G., Molnár, Zs., Kun, A. \& Botta-Dukát, Z. (2000): Landscapes and vegetation along a climatic and edaphic gradient: variability of the sandy grassland in the Hungarian Region. - 
In: Lajtha, K. \& Vanderbilt, K. (eds): Cooperation in Long Term Ecological Research in Central and Eastern Europe. Proceedings of the ILTER Regional Workshop 22-25 June, 1999 Budapest, Hungary, pp. 91-92.

Kovács-Láng, E., Kröel-Dulay, Gy., Kertész, M., Fekete, G., Bartha, S., Mika, J., DobiWantuch, I., Rédei, T., Rajkai, K., \& Hahn, I. (2000): Changes in the composition of sand grasslands along a climatic gradient in Hungary and implications for climate change. - Phytocoenologia 30: 385-407.

Borhidi, A., Berczik, Á., Fekete, G., Jermy, T., Mahunka, S. \& Vida, G. (2000): Ökológiai kutatások az ezredfordulón. - Ezredforduló 2000, 4: 21-26.

Varga, Z., Borhidi, A., Fekete, G., Debreczy, Zs., Bartha, D., Bölöni, J., Molnár, A., Kun, A., Molnár, Zs., Lendvai, G., Szodfridt, I., Rédei, T., Facsar, G., Sümegi, P., Kósa, G. \& Király, G. (2000): Az erdőssztyepp fogalma, típusai és jellemzésük. - In: Molnár, Zs. \& Kun, A. (szerk.): Alföldi erdőssztyepp-maradványok Magyarországon. WWF füzetek 15: 7-19.

Molnár, Zs., Fekete, G., Varga, Z., Kun, A., Sümegi, P., Molnár, A., Facsar, G., Szodfridt, I. \& V. Sipos J. (2000): Az alföldi erdőssztyeppek típusai. - In: Molnár, Zs. \& Kun, A. (szerk.): Alföldi erdőssztyepp-maradványok Magyarországon. WWF füzetek 15: 26-35.

Fekete, G. (2001): Jakucs Pál (1928-2000). - Magyar Tudomány 2001(3): 363-365.

Borhidi, A., Jermy, T., Fekete, G. \& Kovácsné Láng, E. (2001): A kelet-közép-európai ökológiai-természetvédelmi kutatóhálózat hazai tudományos háttere és eszközrendszere. - In: Borhidi, A. \& Botta-Dukát, Z. (szerk.): Ökológia az ezredfordulón I. Koncepció, hosszú távú kutatások. MTA, Budapest, pp. 15-47.

Fekete, G. \& Kun, A. (2001): A Duna-Tisza közi erdei flóra. Chorológiai aszpektusok. - In: Borhidi, A. \& Botta-Dukát, Z. (szerk.): Ökológia az ezredfordulón I. Koncepció, hosszú távú kutatások. MTA, Budapest, pp. 129-131.

Fekete, G., Molnár, Zs., Kun, A. \& Botta-Dukát, Z. (2001): On the structure of the Pannonian forest steppe: grasslands on sand. - Acta Zool. Hung. (nyomdában).

Fekete, G. (2001): Jakucs Pál, a vegetációtudomány kiemelkedő alakja. - Jakucs Pál emlékkötet. Debrecen. (nyomdában). 